\title{
Rejuvenate
}

\section{Setting the scene}

The series of Rejuvenate dialogues are intended to foster debate across a community of practice working on child and youth rights. Our first dialogue examined the principles that can help support child and youth-centred research and community development.

During the dialogue, we highlighted two key REJUVENATE principles: the importance of relationships, and the energy that young people can contribute to building new visions of the future.

We met online on $14^{\text {th }}$ September 2021. Presenters and participants joined from around the world, reflecting the diversity and breadth of experience in the field. We invited reflection on what the REJUVENATE principles get right, where they need to expand, and what they could improve on.

\section{Highlights}

(You can also watch the presentations: https://youtu.be/Fnfi2Y93d80)

\section{Rejuvenate Dialogue
$14^{\text {th }}$ September 2021 \\ Rejuvenate Dialogue
$14^{\text {th }}$ September 2021}

\author{
The REJUVENATE principles \\ Relationships \\ Evolving capacities \\ Justice - personal and social \\ Unusual suspects \\ Visual and creative praxis \\ Empowerment \\ Norms - social and \\ institutional \\ Accountability \\ Transformation \\ Energy
}

Tessa Lewin (Institute of Development Studies) and Vicky Johnson (University of Highlands and Islands) began the dialogue by reflecting on the breadth of experience present. Tessa welcomed policy makers, practitioners, young researchers, academics, and funders who had come to participate. Vicky highlighted the REJUVENATE principles of 'energy', 'relationships' and 'justice' - social, environmental, climate and generational justice.

Presentations began with Kay Tisdall. Kay, Chair of Child Policy at the University of Edinburgh, suggested the UNCRC as an important minimum starting point for work on rights. She argued that child and youth rights need to be seen in the context of human rights, and that relying on Article 12 is not enough. Kay recommended that we all work towards ensuring child rights are meaningful, effective and sustainable within the existing fabric of adult systems and attitudes. She acknowledged that to do this, we need to find the 'energy' to proactively support young people's agency, empowerment and activism.

"The UNCRC is being brought into our domestic laws. So we're really interested in accountability, and what could it mean?... We need to see how we could engage with them ethically... How do we challenge ourselves in terms of which children and young people are being included and which are being excluded?... Let's not have it always be a project. How can we just make it part of everything that we do?" (Kay)

\section{Yello!}

Yello! is Scottish Women's Aid's young expert group. It is comprised of young people who have experience of domestic abuse. Among other projects, they have collaborated with Scottish Women's Aid on the Children (Scotland) Act (2020) and the Improving Justice (IJCC) in Child Contact project. The IJCC is a joint project of the University of Edinburgh and Scottish Women's Aid, along with four other European countries: Romania, Bulgaria, Cyprus and Portugal. The project works with children and young people in each country to improve the way these countries respond to children and young people who have experienced domestic abuse. 
In the next presentation, Jen Uchendu, founder of SustyVibes, expressed her passion and energy for climate activism in Nigeria. She explained that safe spaces can help youth to build relationships and express their feelings about issues they feel anxious about. Jen suggested that we will need to evolve and rethink in order to move to more sustainable futures.

\section{SustyVibes}

SustyVibes describe themselves as 'a community of young people passionately promoting the message of sustainability through engaging projects and events.' Based in Nigeria, SustyVibes organises events and projects to promote sustainable living. They work with schools, recycling and waste management companies and businesses to share knowledge, generate conversations and enact positive change.

Next, Pia MacRae, new Chief Executive Officer for the Consortium for Street Children, highlighted the principles of 'empowerment' and 'evolving capacities'. Drawing on her experiences from China, Pia reflected on the importance of safeguarding children when they are advocating for change. She gave examples of working with children at the CSC where consultation with children formed the basis of their input into the General Comment on Children in Street Situations. She also referenced her collaboration with children in the CLARISSA programme, a consortium that follows a child-centred approach, led by IDS with CSC, ChildHope and Terres Des Hommes, involving children in design, analysis and communication.

\section{Consortium for Street Children}

Consortium for Street Children (CSC) is a global network of over $150+$ community organisations, national and international non-governmental organisations, researchers, advocates and on-the-ground practitioners in 135 countries. CSC is focused on improving the lives of the most marginalised and vulnerable street-connected children. Their work spans three main areas: growing and expanding their network; advocating for policy; and learning and research.

A presentation from Pendekezo Letu in Kenya followed. Programme Coordinator, Okari Magati, and researcher, Serah Wanjiru Mbatia, discussed the UN Girls Education Initiative research with street-connected girls in Nairobi. This project was initially funded by Comic Relief, with recent revisits funded by the Global Challenges Research Fund (GCRF) through University of the Highlands and Islands (UHI). Young women who were street connected told their stories of how 'Covid babies' have affected their young lives in lockdown. As their regular support systems and schools closed, traditional support systems, such as support from grandparents, helped the young mothers.

\section{Pendekezo Letu}

Pendekezo Letu, meaning "our choice" in Swahili, is a Kenyan non-governmental organisation that was established in May 1997 to assist street children and their families to escape abject poverty and lead more fulfilling lives away from the streets and slums of Nairobi, Kenya. Pendekezo Letu supports vulnerable children and other disadvantaged community members in Kenya to fully access their basic rights to education, information, protection from violence, justice, and reproductive health care. 
Lastly, Mark Canavera, Co-Director of Care and Protection of Children Learning Network highlighted the importance of visual and creative praxis in listening to what children say.

"And what we really have to do is learn to undo that and to unlearn to undo the socialisation. learn to undo the adultism. And I think the easiest way is by speaking to children who are children today and now. I think we've heard some really nice examples of that and there are of course many in the living archive. And I don't want to suggest that children are more innocent, because I think that's a very laden and misapplied term, but they have not been socialised into certain ways of thinking and can often think more creatively, and I think justly about the problems in the world today." (Mark)

Mark suggested that what is needed is the magic of 'transformation' and 'energy' rather than checklists and manuals.

\section{CPC Learning Network}

The CPC Learning Network convenes academics, policymakers, and practitioners to promote innovative research, nurture communities of learning, and build the next generation of researchers and advocates for children and families worldwide. CPC develops innovative tools and methodologies to better measure children's care, protection, and welfare. These methods and tools range from program-level evaluations to broader research methods focused at the policy level.

The presentations were followed by discussions in breakout rooms.

Koki and Okari fed back about discussions from two groups that included examples of building inspiring relationships. Projects discussed in these groups included working with girls to provide sanitary pads, and a project that engaged with youth through through basketball.

\section{Pledge a Pad}

Pledge a Pad is a student-run and student-founded organisation at the University of Pretoria in South Africa providing free sanitary products to women and girls and educating young women on feminine hygiene.

One group discussed the need to 'edit social norms' and the importance of 'accountability to children'. The other discussed the need to recognise 'adultism' to unlearn and put right the past mistakes made by not listening to children and youth. Both groups suggested that when youth participation is seen as youth activism, it is often seen as a threat to adult power, and this can limit young people's involvement in community development and policy making processes. There are challenges around longevity in funding and grant-making and building on partnerships with the field principles of REJUVENATE embedded.

Raisa's group echoed Kay's insistence on the importance of acountability to children and youth, in participatory programming and grant making. The group suggested that everyone working with children would need to be inspired by the energy of young people to help politicians make the right decisions! This group also discussed the importance of methods that help to understand developing identities including gender and sexuality being part of supporting young people's evolving capacities.

Jen rounded up the dialogue, reporting back from her group on the importance of avoiding tokenism and supporting more meaningful participation. She argued that conversations can change imaginations, and that her group had discussed making room for experimentation. It was suggested that young people need dedicated spaces in order to find synergy with each other. This fits with Rejuvenate's call to deepen child/youth participation through extending the 3Ps of the UNCRC to the 3SS - 'space, support and systems change'. 


\section{Building connections}

Attendees included adults and youth researchers from across the globe in conversation with a range of decision makers and funders. Organisations can be seen on the map below.

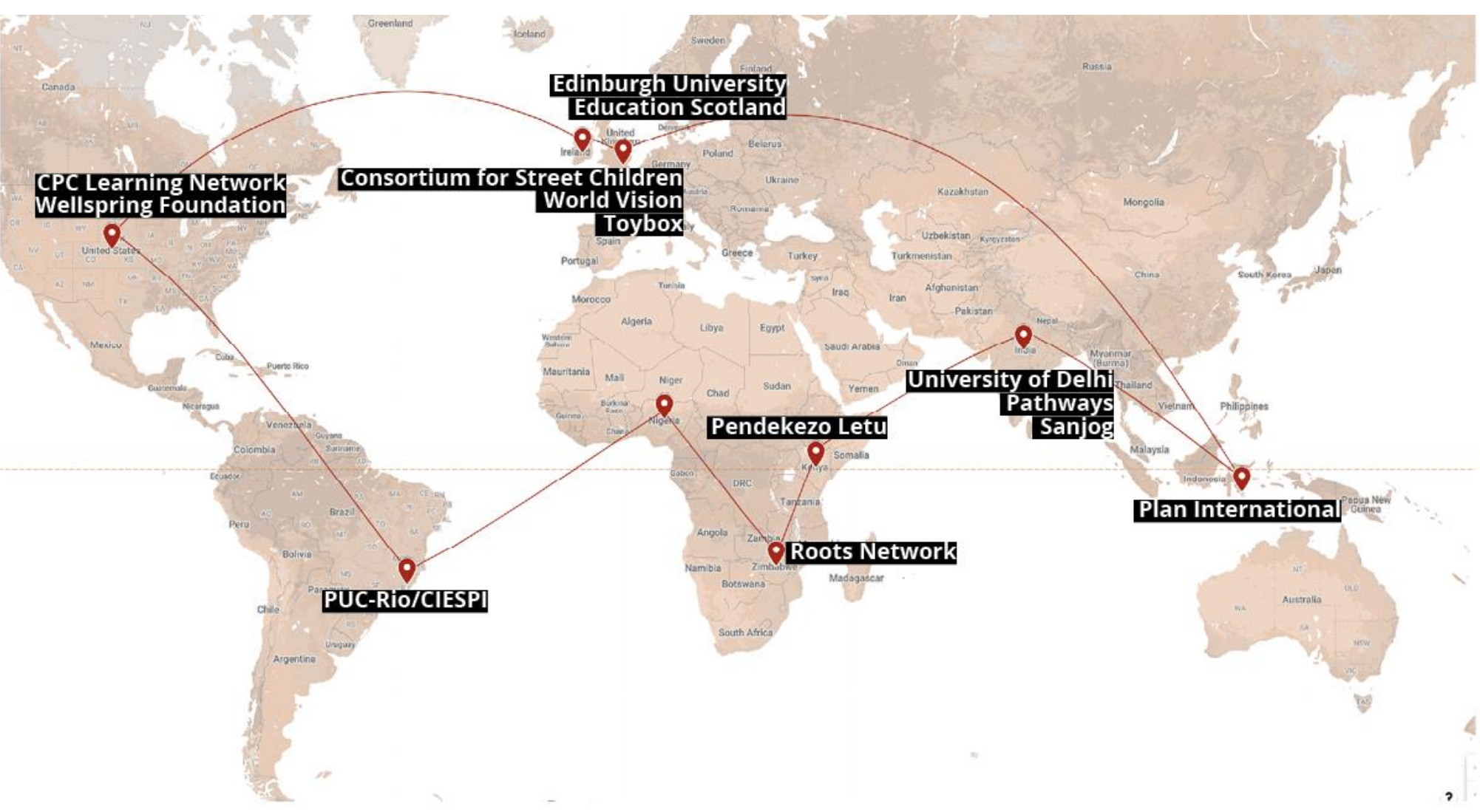

Source: Map data @2021 Google, INEGI

\section{Continuing the conversation}

Blogs - REJUVENATE keep conversations around child and youth rights going through regular blogs. If you have an idea for a blog, please do get in touch with one of the REJUVENATE team via our website. Check out some of our latest blogs below:

- $\quad$ Speaking youth to power at COP26

- Disrupting adultism in the climate change conversation

- An Africa fit for children

- Unlikely networks: Driving accountability through grassroot youth voices

- Collective impact: Children and young people as partners in social change projects

- Safeguarding for youth activism: Taking a feminist approach.

Explore and submit to our Living Archive - a collection of organisations, projects and resources all focused on child and youth rights and participation. We've included some examples in boxes in this paper. If you have an item you think others in the field can learn from, please fill out our submission form.

Next REJUVENATE dialogue - we'll be continuing the conversation at $12 \mathrm{pm}$ on Thursday $2^{\text {nd }}$ December. This time, we'll be focusing on Covid-19 and how it has impacted child and youth rights. You can register for the event on Zoom here. 